\title{
Variation of cervical cancer incidence in Latin America and the Caribbean
}

\author{
Christine M. Pierce Campbell, ${ }^{1}$ Maria Paula Curado, ${ }^{2}$ \\ Siobán D. Harlow, ${ }^{1}$ and Amr S. Soliman ${ }^{1}$
}

Suggested citation Pierce Campbell CM, Curado MP, Harlow SD, Soliman AS. Variation of cervical cancer incidence in Latin America and the Caribbean. Rev Panam Salud Publica. 2012;31(6):492-8.

\begin{abstract}
Objective. To provide a comprehensive analysis of the descriptive epidemiology of invasive cervical cancer in Latin America and the Caribbean by analyzing quality data from the area's cancer registries, including data that were excluded from the International Agency for Research on Cancer (IARC) publication, Cancer Incidence in Five Continents, Vol. IX (CI5-IX).

Methods. This was a descriptive epidemiologic study that involved 20 cancer registries, 9 of which were included by IARC in CI5-IX, and 11 of which were not. Data on invasive cervical cancers diagnosed from 1998-2002 were obtained from IARC. A cervical cancerspecific quality assessment was performed on all registries whether or not they were included in CI5-IX. Data from 14 registries met quality criteria and were analyzed. Incidence rates were calculated and compared across registries.

Results. A substantial variation in incidence rates existed among the registries; agestandardized rates ranged from 14.6-44.0 per 100000 women per year. Mean cervical cancer incidence rates were $10.4 \%$ higher for registries included in CI5-IX than for those excluded; however, this difference was not significant $(\mathrm{P}=0.541)$.

Conclusions. This study compared cervical cancer rates from a more diverse group of Latin American and Caribbean countries than that of the CI5-IX. The heterogeneity found among registries highlights the importance of examining data from as many registries as possible when characterizing risk across a geographic area. Data from developing countries can be used to better understand cancer distribution and enable Region-specific recommendations on cancer control and prevention once data quality has been established.
\end{abstract}

Key words Uterine cervical neoplasms; incidence rate; Latin America; Caribbean region.

Cervical cancer remains a significant global health problem despite the fact that it is highly preventable. With an estimated 529800 new cases and 275100

1 Department of Epidemiology, School of Public Health, University of Michigan, Ann Arbor, Michigan, United States of America.

2 Cancer Information Section, International Agency for Research on Cancer (IARC), Lyon, France. Send correspondence to Maria Paula Curado, email: maria-paula.curado@i-pri.org deaths in 2008, it is the third most common cancer among women worldwide $(1,2)$. More than $85 \%$ of the global burden and $88 \%$ of the global mortality due to cervical cancer occur in developing countries, where it is the second most common cancer among women $(1,2)$. Although the incidence of cervical cancer is declining worldwide, high rates persist in many areas of Africa, Latin America, and South Asia $(1,3,4)$.
Cancer registries play an important role in building infrastructure for essential health research, producing statistics on disease occurrence, and monitoring trends in cancer incidence by collecting, coding, and classifying cancer cases (5, 6). The International Agency for Research on Cancer (IARC) has published data from population-based cancer registries routinely since the 1970s. Its publication, Cancer Incidence in Five Con- 
tinents (CI5), records the worldwide burden of cancer by compiling comparable cancer incidence data from a wide range of geographic locations. The CI5 covers 5-year periods, most recently from 1998-2002 (5).

Prior to publication, the IARC invites cancer registries to submit their data to CI5 editors (5). Data quality is then evaluated by an editorial board using IARC international standards and defined quality criteria $(5,7)$. The indicators used by CI5 editors to assess the comparability, validity, and completeness of registry data are based on data used to estimate overall cancer rates, from all cancer sites combined, during the assessment period $(5,7)$. Therefore, if a registry submits data that does not meet quality criteria for all cancer sites combined, data from the entire cancer registry will be excluded, regardless of the quality of the data available for any individual cancer site. Since they are often lethal or difficult to diagnose, certain cancers-such as pancreatic, liver, and esophageal-may lower overall data quality when combined with other cancer sites (8-10).

Cervical cancer and its precursor lesions, on the other hand, are potentially more easily diagnosed, and therefore, data quality may be higher for this cancer site. The uterine cervix is accessible for physical examination and detection of early cervical precursor lesions. Furthermore, cervical cancer and its precursor lesions have well-established diagnostic criteria and available technologies for detection and diagnosis, such as cytology-based screening (11). Although few organized cervical cancer screening programs exist in Latin America and the Caribbean, opportunistic screening programs have been implemented, thereby increasing cervical cancer awareness in the area $(12,13)$.

In Latin America and the Caribbean, 29 cancer registries from 11 countries submitted data to IARC for inclusion in CI5 Volume IX (CI5-IX); however, only 11 registries from 8 countries were actually included (5). Data from 18 registries were excluded by CI5-IX due to insufficient data quality for all cancer sites combined. Given the current level of interest in cervical cancer burden and prevention, the 11 registries included in CI5-IX may only partially represent the cancer incidence in different geographic areas within Latin America and the Ca- ribbean. Evaluation of information from more cancer registries may lead to a better understanding of the profile and descriptive epidemiology of cervical cancer in this part of the world.

The study objective was to provide a comprehensive analysis of the descriptive epidemiology of invasive cervical cancer based on data from population-based cancer registries in Latin America and the Caribbean that were both included and excluded from CI5-IX, after first ascertaining that the quality of cervical cancer reporting was adequate. Any systematic variation in incidence rates among included and excluded registries was determined by examining age-standardized, histopathology-specific, and age-specific rates.

\section{METHODS}

This was a descriptive epidemiologic study. Invitation letters requesting permission to evaluate invasive cervical cancer data were sent to all 29 cancer registries in Latin America and the Caribbean that had submitted data to the CI5-IX. Of those, 20 granted permission for this analysis; 9 did not. Of the 20 granting permission, 9 had been included in CI5-IX (Bahía Blanca, Argentina; Brasília, Brazil; Cuiabá, Brazil; Goiânia, Brazil; São Paulo, Brazil; Cali, Colombia; Costa
Rica; Quito, Ecuador; and Trujillo, Peru), and 11 had been excluded (Curitiba, Brazil; Fortaleza, Brazil; João Pessoa, Brazil; Salvador, Brazil; Cuba; Santiago de Cuba, Cuba; Villa Clara, Cuba; Guatemala; Arequipa, Peru; Lima, Peru; and Trinidad and Tobago). Figure 1 shows the process used to decide which registries would be included in the present study analysis. Each cancer registry provided annual data on invasive cervical cancer cases and corresponding population estimates. The Institutional Review Board at the University of Michigan (Ann Arbor, Michigan, United States) approved the study proposal.

Statistical analyses were performed with Microsoft Excel ${ }^{\mathrm{TM}}$ (Microsoft Corp., Redmond, Washington, United States) and SAS/STAT software (Version 9; SAS Institute, Cary, North Carolina, United States). First, a quality assessment was conducted using only invasive cervical cancer data to determine whether each registry had sufficient data quality. International standards for quality criteria were employed. The same quality indicators used by IARC for all cancer sites combined in CI5-IX were used to examine the quality of cervical cancer data $(5,7)$. These indicators included the proportion of cases microscopically verified (MV\%), registered from a death certificate only (DCO\%), and with an

FIGURE 1. Flow chart describing which registries from Latin America and the Caribbean were included in or excluded from Cancer Incidence in Five Continents, Vol. IX (Cl5-IX), and which were analyzed or not analyzed in the current study

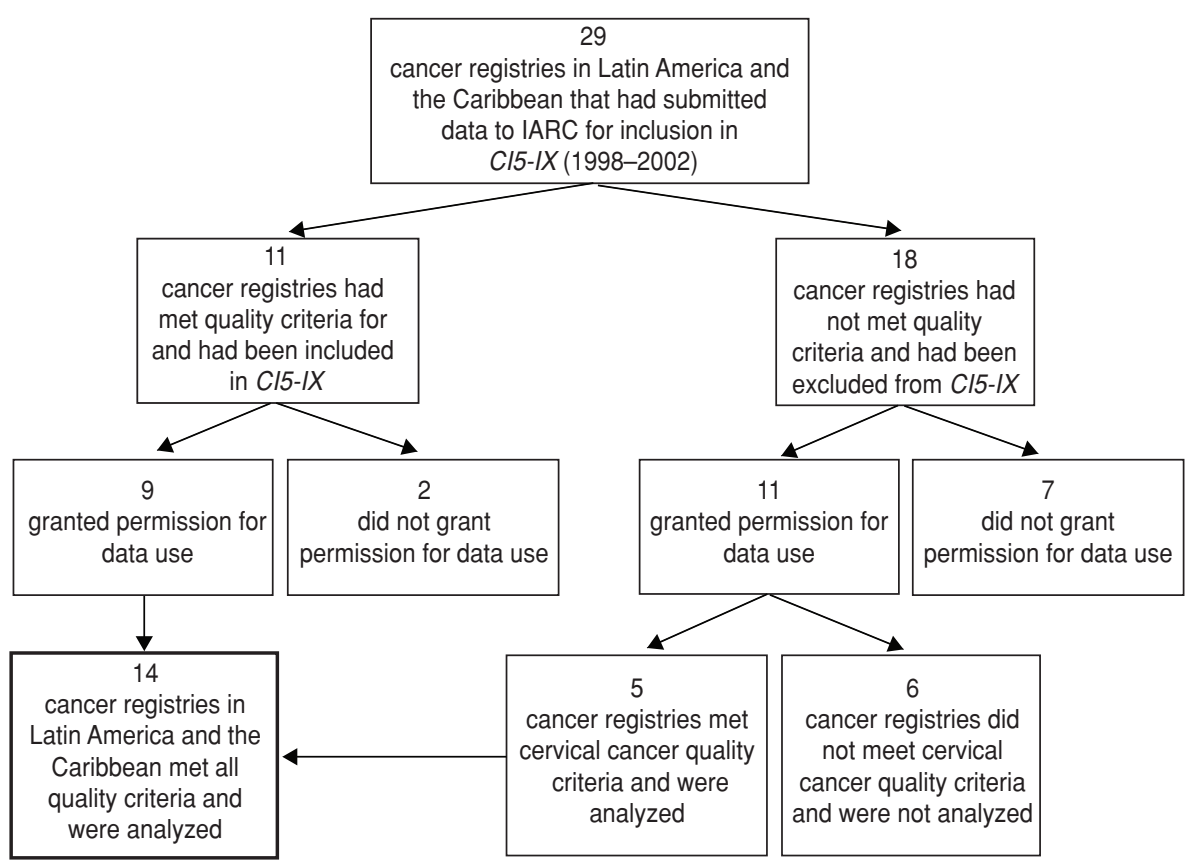


unknown basis of diagnosis (UB\%) (5). The acceptable limits for data quality indicators were based on international standards and modified by the authors to better reflect cervical cancer data: $\mathrm{MV} \%, 75 \%-98 \%$; $\mathrm{DCO} \%$, < 10\%; and $\mathrm{UB}<10 \%$. It should be noted that while a high $\mathrm{MV} \%$ is desirable in developed countries, a value that is near perfect in developing countries suggests an overreliance on pathology laboratories in diagnosing cervical cancer cases, and an inability to locate cases diagnosed by other means (14). The cervical cancer-specific quality assessment was performed on all registries that had been either included in or excluded from the CI5-IX publication. Subsequent analyses were performed on all registries that met the necessary quality criteria for cervical cancer data.

Age-standardized cervical cancer incidence rates were calculated for each population-based cancer registry over the 5-year time period 1998-2002 (the same years covered by CI5-IX), and were expressed as the number of new cervical cancer cases per 100000 women per year $(5,15)$. Histopathology-specific age-standardized incidence rates were calculated for each of the two most common histopathologic types of cervical cancer, squamous cell carcinoma (SCC) and adenocarcinoma (ADC) (16), using the method described above. Associated 95\% Confidence Intervals (95\% CI) were approximated based on the assumption of normally distributed rates $(5,15)$.

Crude, age-specific incidence rates for cervical cancer were calculated for women 15-64 years of age. No cervical cancer cases were reported in women $<15$ years of age in the registries analyzed. Incidence rates for women $>64$ years of age were not calculated due to the sharp decline in incidence rates observed among older age groups in many registries. This fall-off of cervical cancer incidence rates at older ages may indicate under-ascertainment of cases in those age groups, and therefore, the age-specific incidence rates for these age groups were disregarded $(17,18)$.

The effect of CI5-IX inclusion status on registry-specific cervical cancer incidence rates (i.e., to compare whether or not the rates for registries included in CI5-IX differ significantly from those excluded) was examined using a generalized linear mixed model. This model was designed to estimate the betweenregistry variation in cervical cancer incidence among the population-based cancer registries under study. The final model for registry-specific cervical cancer incidence rates included the following covariates: year, age group, an interaction term for year and age group, and inclusion status. Data from two of the three Cuban cancer registries (Santiago de Cuba and Villa Clara) were removed from this regression analysis because of the overlap in cases with the national cancer registry of Cuba. Regression models were generated using the GLIMMIX procedure in SAS/STAT ${ }^{\circledR}$ software.

\section{RESULTS}

Table 1 highlights the results from the cervical cancer-specific data quality assessment undergone by each of the 20 participating cancer registries. All 9 registries that had been included in CI5-IX met the cervical cancer-specific quality requirements, as did 5 of the 11 excluded registries. Of the 6 that did not meet the quality requirements and were removed from the analysis, 3 exceeded the ac-

TABLE 1. Cervical cancer data quality-assessment for the 20 cancer registries that granted permission for data use, Latin America and the Caribbean, 1998-2002

\begin{tabular}{|c|c|c|c|c|c|c|c|}
\hline & \multirow{3}{*}{$\begin{array}{c}C l 5-I X^{a} \\
\text { inclusion } \\
\text { (yes/no) }\end{array}$} & \multirow{3}{*}{$\begin{array}{l}\text { Registration } \\
\text { time period }\end{array}$} & \multirow{3}{*}{$\begin{array}{l}\text { Population, } \\
\text { females } \\
(n)\end{array}$} & \multirow{3}{*}{$\begin{array}{c}\text { Cervical } \\
\text { cancer cases } \\
\text { No. }\end{array}$} & $\begin{array}{c}\text { Microscopically } \\
\text { verified } \\
(\%)\end{array}$ & $\begin{array}{c}\text { Death } \\
\text { certificate } \\
\text { only } \\
(\%)\end{array}$ & $\begin{array}{l}\text { Unknown } \\
\text { basis of } \\
\text { diagnosis } \\
(\%)\end{array}$ \\
\hline & & & & & \multicolumn{3}{|c|}{ Acceptable range } \\
\hline & & & & & $75 \%-98 \%$ & $\leq 10 \%$ & $\leq 10 \%$ \\
\hline \multicolumn{8}{|l|}{ Registries analyzed } \\
\hline Bahía Blanca (Argentina) & Yes & 1998-2002 & 147977 & 139 & 95.0 & 2.9 & 2.2 \\
\hline Brasília (Brazil) & Yes & 1998-2001 & 1047388 & 1154 & 91.2 & 2.2 & 6.3 \\
\hline Cuiabá (Brazil) & Yes & 2000-2002 & 362919 & 302 & 89.1 & 5.6 & 2.6 \\
\hline Fortaleza (Brazil) & No & 1998-1999 & 1105401 & 581 & 91.0 & 4.8 & 0.7 \\
\hline Goiânia (Brazil) & Yes & 1999-2002 & 574049 & 711 & 98.5 & 1.1 & 0.1 \\
\hline São Paulo (Brazil) & Yes & 1998-2002 & 5444354 & 6028 & 85.6 & 4.1 & 0.0 \\
\hline Cali (Colombia) & Yes & 1998-2002 & 972645 & 1314 & 93.8 & 2.1 & 0.0 \\
\hline Costa Rica & Yes & 1998-2002 & 1927041 & 1655 & 89.2 & 3.3 & 0.0 \\
\hline Cuba & No & 1998-2002 & 6039915 & 6369 & 91.7 & 0.0 & 8.0 \\
\hline Santiago de Cuba (Cuba) & No & 1998-2002 & 523370 & 790 & 94.8 & 1.6 & 0.0 \\
\hline Villa Clara (Cuba) & No & 1998-2002 & 423800 & 393 & 95.2 & 3.3 & 0.0 \\
\hline Quito (Ecuador) & Yes & 1998-2002 & 734477 & 637 & 93.4 & 3.9 & 0.0 \\
\hline Lima (Peru) & No & 1998 & 3653980 & 728 & 88.6 & 4.5 & 0.0 \\
\hline Trujillo (Peru) & Yes & 1998-2002 & 312412 & 498 & 96.2 & 2.6 & 0.0 \\
\hline \multicolumn{8}{|l|}{ Registries not analyzed } \\
\hline Curitiba (Brazil) & No & 1998-2000 & 818170 & 561 & 79.3 & 13.0 & 6.1 \\
\hline João Pessoa (Brazil) & No & 1999-2002 & 320987 & 260 & 100.0 & 0.0 & 0.0 \\
\hline Salvador (Brazil) & No & 1998-2002 & 1273529 & 663 & 85.5 & 11.9 & 1.8 \\
\hline Guatemala $^{\mathrm{b}}$ & No & 1998-2002 & 1301228 & 1297 & 97.8 & 0.0 & 0.0 \\
\hline Arequipa (Peru) ${ }^{c}$ & No & 2002 & 197103 & 258 & 98.3 & 0.0 & 0.0 \\
\hline Trinidad and Tobago & No & 1998-2002 & 629315 & 584 & 83.9 & 15.1 & 0.0 \\
\hline
\end{tabular}

a Cancer Incidence in Five Continents, Vol. IX.

b Hospital-based cancer registry.

c Newly established cancer registry. 
ceptable proportion of cases registered from a death certificate only (Curitiba, Brazil; Salvador, Brazil; and Trinidad and Tobago); 1 exceeded the acceptable proportion of cases microscopically verified (João Pessoa, Brazil); 1 was in its first year of operation (Arequipa, Peru), and 1 was a hospital-based rather than population-based cancer registry (Guatemala). While these registries did not meet this study's requirements, they may be suitable for the needs of other studies at a local level. In all, a total of 14 population-based cancer registries met the necessary quality requirements for cervical cancer diagnosis and were analyzed in this study.

In Table 2, age-standardized cervical cancer incidence rates are provided for the 14 Latin American and Caribbean population-based cancer registries under study. These rates demonstrated a wide range of values (14.6-44.0 per 100000 women per year). The Trujillo, Peru registry, included in CI5-IX, reported the highest age-standardized rate, 44.0; while Villa Clara, Cuba, a registry excluded from CI5-IX, reported the lowest rate, 14.6. The highest rates (33.9-44.0) were reported by registries included in CI5-IX: Goiânia, Brazil; Brasília, Brazil; Cuiabá, Brazil; and Trujillo, Peru; however, the intermediate rates (22.4-33.1) were reported mostly by registries that had been excluded from CI5-IX (Lima, Peru; Santiago de Cuba, Cuba; and Fortaleza, Brazil). The lowest rates (14.621.1) were reported by an assortment of registries, some of which had been included in CI5-IX, and some, excluded.
When incidence rates were compared between pairs of registries, most rates were significantly different from the other (data not shown).

Age-standardized incidence rates for the two most prevalent histopathologic types of cervical cancer, squamous cell carcinoma (SCC) and adenocarcinoma (ADC), are also given in Table 2. Rates ranged from 9.1-37.3 for cervical SCC, and 1.1-3.6 for cervical ADC. Similar to results for overall cervical cancer incidence, Trujillo, Peru, reported an SCC incidence rate of 37.3 , the highest; while Villa Clara, Cuba, reported 9.1, the lowest. Brasília, Brazil, reported the highest ADC incidence rate, 5.0; while Villa Clara, Cuba, reported the lowest, 1.1.

In Figure 2, age-specific cervical cancer incidence curves are illustrated for each registry. Across the 14 registries examined, the incidence of cervical cancer generally increases with age, as expected. However, the patterns of age-specific incidence curves fluctuated considerably. Some curves rise consistently as age increases, while others rise sharply and level off at older age groups; this phenomenon could be related to the under-ascertainment of cervical cancer cases in older age groups $(17,18)$.

The generalized linear mixed model shows that after controlling for year and age group, the mean cervical cancer incidence rates were $10.4 \%$ higher for those registries that had been included in CI5-IX than for those excluded; however, these results were not statistically significant $(\beta=0.099, P=0.541)$. Furthermore, the estimated variance between registries (0.050) was smaller than the variance among different age groups within each registry (0.557).

\section{DISCUSSION}

Using incidence data from 14 population-based cancer registries across Latin America and the Caribbean, this study provided a comprehensive analysis of invasive cervical cancer incidence among registries included and excluded by CI5-IX. This is the first study to examine variation in cervical cancer incidence among this large a number of Latin American and Caribbean cancer registries for the time period 1998-2002. By observing age-standardized, histopathology-specific, and age-specific cervical cancer incidence rates, heterogeneity among registries was found, confirming the heterogeneity found in prior studies (19-21). These results highlight the importance of examining data from as many registries as possible when characterizing risk across a geographic area, and emphasize the usefulness of incidence data, particularly in resourcepoor areas.

Age-standardized incidence rates demonstrated a wide range of values (14.6-44.0), as did histopathologyspecific rates (SCC: 9.1-37.3; ADC: 1.13.6) and age-specific rates (Table 2). The heterogeneity in cervical cancer incidence rates among the registries examined may be related to the data quality of each cancer registry (15); however, it may also be influenced by the presence or absence of organized screening

TABLE 2. Age-standardized cervical cancer incidence rates and $95 \%$ confidence intervals, by histopathologic type and registry, Latin America and the Caribbean, 1998-2002

\begin{tabular}{|c|c|c|c|c|c|c|c|}
\hline \multirow[b]{2}{*}{ Registry } & \multirow{2}{*}{$\begin{array}{c}C l 5-I X^{a} \\
\text { inclusion } \\
\text { (yes/no) }\end{array}$} & \multicolumn{2}{|c|}{ Cervical cancer overall } & \multicolumn{2}{|c|}{$\begin{array}{c}\text { Squamous cell carcinoma } \\
\text { (SCC) }\end{array}$} & \multicolumn{2}{|c|}{$\begin{array}{c}\text { Adenocarcinoma } \\
\text { (ADC) }\end{array}$} \\
\hline & & $\mathrm{ASR}^{\mathrm{b}}$ & $95 \% \mathrm{Cl}^{\mathrm{C}}$ & ASR & $95 \% \mathrm{Cl}$ & ASR & $95 \% \mathrm{Cl}$ \\
\hline Trujillo (Peru) & Yes & 44.0 & $40.0-47.9$ & 37.3 & $33.6-40.9$ & 3.6 & $2.5-4.8$ \\
\hline Cuiabá (Brazil) & Yes & 37.7 & $33.2-42.2$ & 27.2 & $23.4-31.1$ & 3.8 & $2.4-5.2$ \\
\hline Brasília(Brazil) & Yes & 37.7 & $35.4-40.0$ & 24.4 & $22.5-26.2$ & 5.0 & $4.1-5.8$ \\
\hline Goiânia (Brazil) & Yes & 33.9 & $31.3-36.5$ & 24.1 & $21.9-26.3$ & 4.9 & $3.9-5.8$ \\
\hline Fortaleza (Brazil) & No & 33.1 & $30.4-35.9$ & 22.3 & $20.1-24.6$ & 2.5 & $1.8-3.2$ \\
\hline Cali (Colombia) & Yes & 27.9 & $26.4-29.4$ & 19.8 & $18.5-21.0$ & 3.0 & $2.5-3.5$ \\
\hline Santiago de Cuba (Cuba) & No & 26.4 & $24.5-28.2$ & 21.9 & $20.2-23.6$ & 1.5 & $1.0-2.0$ \\
\hline Lima (Peru) & No & 22.4 & $20.8-24.1$ & 13.9 & $14.2-17.0$ & 2.8 & $2.2-3.4$ \\
\hline São Paulo (Brazil) & Yes & 21.1 & $20.5-21.6$ & 13.7 & $13.3-14.1$ & 2.7 & $2.5-2.9$ \\
\hline Quito (Ecuador) & Yes & 20.0 & $18.4-21.7$ & 16.1 & $14.6-17.5$ & 2.0 & $1.5-2.5$ \\
\hline Costa Rica & Yes & 18.9 & $18.0-19.9$ & 13.7 & $12.9-14.5$ & 2.6 & $2.2-2.9$ \\
\hline Cuba & No & 17.6 & $17.1-18.0$ & 16.1 & $13.1-13.9$ & 1.2 & $1.0-1.3$ \\
\hline Bahía Blanca (Argentina) & Yes & 16.0 & $13.3-18.8$ & 11.4 & $9.1-13.8$ & 1.3 & $0.6-2.1$ \\
\hline Villa Clara (Cuba) & No & 14.6 & $13.1-16.1$ & 9.1 & $7.9-10.3$ & 1.1 & $0.7-1.5$ \\
\hline
\end{tabular}


FIGURE 2. Age-specific cervical cancer incidence rates per 100000 women annually, by registry, Latin America and the Caribbean, 1998-2002

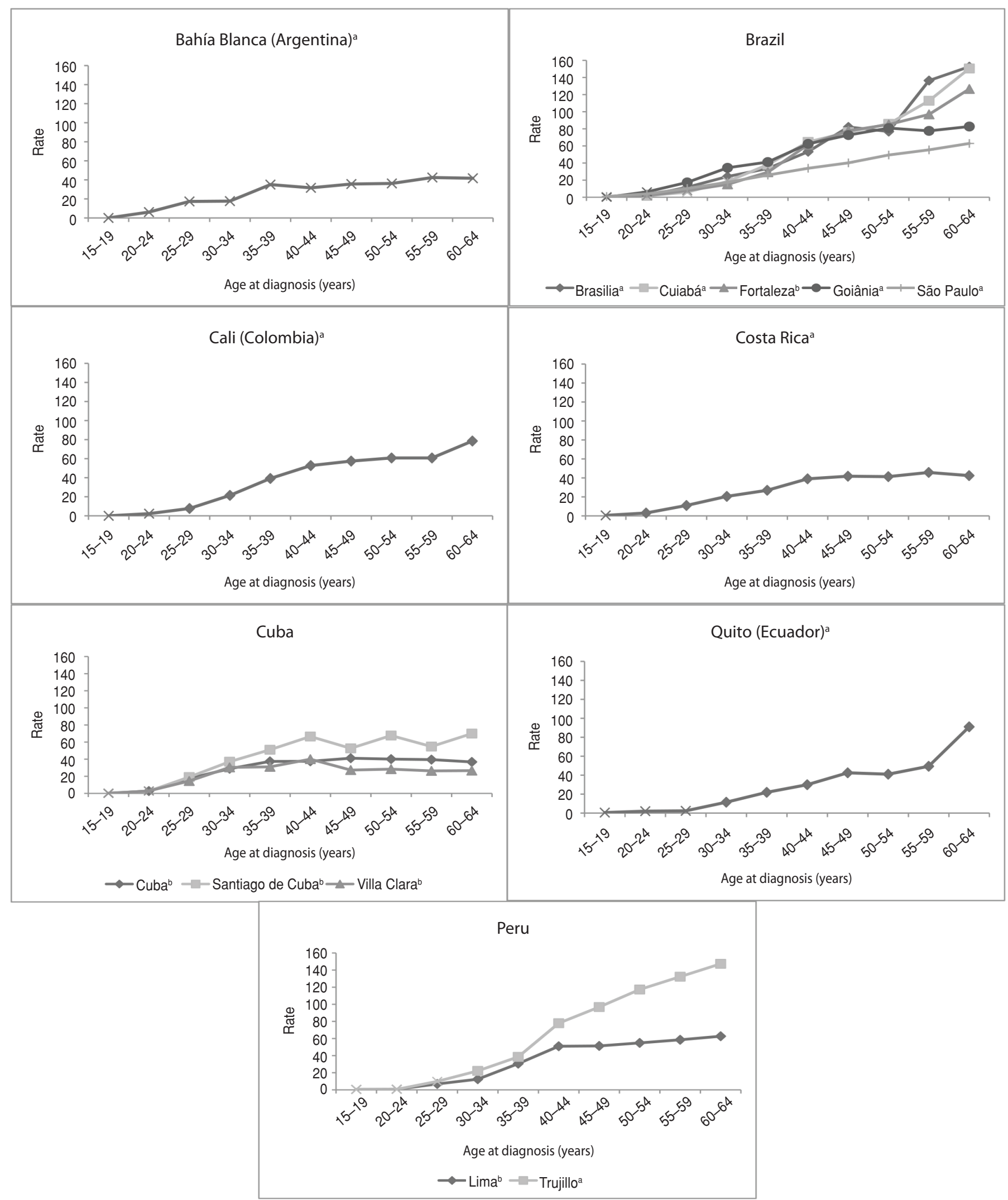

Note: $\times$ denotes a rate based on fewer than 20 cases.

a Included in Cancer Incidence in Five Continents, Vol. IX (CI5-IX).

b Excluded from C/5-IX. 
programs within the geographic areas covered by these registries, as well as differences in the prevalence of cervical cancer risk factors (12). Furthermore, geographic variation may exist in the efficiency of health care systems, where access to diagnostic and treatment facilities for all socioeconomic levels could vary accordingly; this might also contribute to the heterogeneity found in this study (7).

Across the Latin America and the Caribbean, screening practices vary widely. Costa Rica has had opportunistic cytological screening available since the 1970s, but a national screening program did not begin until 1995 (12). Brazil launched a national cytology-based cervical cancer screening program in 1998; however, this program has only been considered successful in a few areas of Brazil (12). Peru, a country with some of the highest cervical cancer incidence rates in Latin America and the Caribbean, has made cervical cancer a national priority for decades; however, despite creating a national plan in 1998 that outlined strategies for cervical cancer prevention, low screening coverage persists $(22,23)$. Argentina also created a national program against cervical cancer in 1998, which was never fully implemented; therefore, in 2008 a national project improvement program began (24). Future research needs to further elucidate the effect of cervical cancer screening programs, both organized and opportunistic, on cervical cancer incidence in the Region.

The CI5 publications routinely report on cancer incidence in Latin America and the Caribbean; however, a disproportionate number of registries in developing countries have been excluded due to inadequate data quality (5). As technology advances and registration practices become more efficient, data quality has improved (5), but many cancer registries in developing countries have not had the opportunity to take advantage of such technological advances especially in comparison with more developed countries (6). Furthermore, financial support for cancer registries in developing countries is often inconsistent. Since many registries rely heavily on government funding, changes in the local political climate easily threaten the sustainability of cancer registries in developing countries. Without funding, cancer registries may be forced to suspend registration-related activities until new sources of funding can be obtained, which may severely impact data continuity and quality. Increasing the utilization of low-cost technology, such as webbased cancer registration, and securing long-term, stable sources of funding may improve the overall data quality of cancer registries in developing countries.

A potential limitation of this study is that only two registries had nationwide coverage (Costa Rica and Cuba); all others were cancer registries covering large, urban centers. Also, women living in rural areas were not represented because there are no cancer registries for rural parts of Latin America and the Caribbean. As a result, the findings and conclusions of this study should only be generalized to urban women. However, despite an inability to document cervical cancer incidence in rural areas, it can be assumed that rates for late-stage cervical cancers are higher in rural than in urban areas. In rural areas, where cervical cancer screening facilities are limited and pre-cancerous cervical lesions are more likely to go undetected, a larger number of late-stage, invasive cervical cancers would be expected. To accurately assess cervical cancer incidence among women in Latin America and the Caribbean, more cancer registries should be implemented in rural areas.

Additional limitations should be considered. Only 20 of the 29 cancer registries included in CI5-IX granted permission for use of their data in this study. Had a larger number of registries been analyzed, it is likely that greater heterogeneity would have been seen. Despite performing a cervical cancerspecific quality assessment to ensure that only high quality cervical cancer data were included, data provided by registries excluded from CI5-IX should be interpreted with caution, as they may not represent valid or reliable estimates of cervical cancer incidence (5). Nonetheless, this analysis broadens the understanding of the cervical cancer profile in Latin America and the Caribbean.

One of this study's strengths is its methodology - a novel approach that first assessed the quality of the cervical cancer-specific data of each cancer registry. This permitted a greater number of Latin American and Caribbean registries to be included in the analysis than were in the CI5-IX, and yet, it is unlikely that quality was compromised.

The study's comparative nature is also a strength. Much can be learned about cervical cancer prevention and control by comparing cervical cancer incidence rates within such a geographically diverse area. Lessons learned from this study could be applied to other low- to middle-income countries where limited data are available. Additionally, similar analyses could be performed for other cancer sites, especially if those cancers are considered preventable and of high priority for public health policy.

\section{Conclusions}

Cervical cancer incidence rates in Latin America and the Caribbean vary greatly by geographic area. The full extent of this variation is not apparent in the CI5-IX, which includes only 11 cancer registries and excludes 18. The current study, however, provides a more complete picture of cervical cancer incidence by using existing data, conducting a data quality assessment, and performing an in-depth evaluation of one cancer site (cervical cancer). Therefore, we recommend using any population-based cancer registries (that have passed a quality assessment) in low- and middle-income countries to better understand cancer distribution, screening programs, and health care systems, and thereby enable Region-specific recommendations on cancer control and prevention interventions.

Acknowledgements. The authors acknowledge the contribution of Rod J. Little and Kathy B. Welch in the preparation of data and statistical analyses, along with Carolyn M. Johnston and Kathy R. Cho for assistance in classifying histopathologic types. The authors would also like to thank the 20 cancer registry directors who provided permission for data use (Arequipa, Bahía Blanca, Brasília, Cali, Costa Rica, Cuba, Cuiabá, Curitiba, Fortaleza, Goiânia, Guatemala, João Pessoa, Lima, Quito, Salvador, São Paulo, Santiago de Cuba, Trujillo, Trinidad and Tobago, and Villa Clara).

Christine Pierce Campbell was supported in part by a number of grants from the University of Michigan (Ann Arbor, Michigan, United States), specifically from the Department of Epidemiology, Rackham Graduate School, Cancer Epidemiology Education in Special Populations (R25 CA112383), Center for the Education of Women, and Institute for Research on Women and Gender. 


\section{REFERENCES}

1. Ferlay J, Shin HR, Bray F, Forman D, Mathers C, Parkin DM. Estimates of worldwide burden of cancer in 2008: GLOBOCAN 2008. Int J Cancer. 2010;127(12):2893-917.

2. Jemal A, Bray F, Center MM, Ferlay J, Ward E, Forman D. Global cancer statistics. CA Cancer J Clin. 2011;61(2):69-90.

3. Sankaranarayanan R, Ferlay J. Worldwide burden of gynaecological cancer: the size of the problem. Best Pract Res Clin Obstet Gynaecol. 2006;20(2):207-25.

4. Wilson CM, Tobin S, Young RC. The exploding worldwide cancer burden: the impact of cancer on women. Int J Gynecol Cancer. 2004;14(1):1-11.

5. Curado MP, Edwards B, Shin HR, Storm H, Ferlay J, Heanue M, et al. Cancer incidence in five continents, Volume IX. Lyon, France: IARC Press; 2007.

6. Jensen OM, Parkin DM, MacLennan R, Muir CS, Skeet RG. Cancer registration: principles and methods. Lyon, France: IARC Press; 1991.

7. Curado MP, Voti L, Sortino-Rachou AM. Cancer registration data and quality indicators in low and middle income countries: their interpretation and potential use for the improvement of cancer care. Cancer Causes Control. 2009;20(5):751-6.

8. Cabibbo G, Craxi A. Epidemiology, risk factors and surveillance of hepatocellular carcinoma. Eur Rev Med Pharmacol Sci. 2010;14(4):352-5.

9. Galasso D, Carnuccio A, Larghi A. Pancreatic cancer: diagnosis and endoscopic staging. Eur Rev Med Pharmacol Sci. 2010;14(4):375-85.
10. Herszenyi L, Pregun I, Tulassay Z. Diagnosis and recognition of early esophageal neoplasia. Dig Dis. 2009;27(1):24-30.

11. International Agency for Research on Cancer, World Health Organization. IARC Handbook of cancer prevention: cervix cancer screening, Volume 10. Lyon, France: IARC Press; 2005.

12. Murillo R, Almonte M, Pereira A, Ferrer E, Gamboa OA, Jeronimo J, et al. Cervical cancer screening programs in Latin America and the Caribbean. Vaccine. 2008;26 (Suppl 11):L37-48.

13. Sankaranarayanan R, Budukh AM, Rajkumar R. Effective screening programmes for cervical cancer in low- and middle-income developing countries. Bull World Health Organ. 2001;79(10):954-62.

14. Parkin DM, Bray F. Evaluation of data quality in the cancer registry: principles and methods Part II. Completeness. Eur J Cancer. 2009;45(5):756-64.

15. Esteve J, Benhamou E, Raymond L. Statistical methods in cancer research, Volume IV: descriptive epidemiology. Lyon, France: IARC Press; 1994

16. Boyle P, Levin B. World cancer report 2008. Lyon, France: IARC Press; 2008.

17. Fallah M, Kharazmi E. Correction for underascertainment in cancer cases in the very elderly (aged 75+): external reference method. Cancer Causes Control. 2008;19(7):739-49.

18. Parkin DM, Chen VW, Ferlay J, Galceran J, Storm HH, Whelan SL, eds. Completeness, comparability and quality control in cancer registration. Lyon, France: IARC Press; 1998.
19. Arrossi S, Sankaranarayanan R, Parkin DM. Incidence and mortality of cervical cancer in Latin America. Salud Publica Mex. 2003;45 Suppl 3:S306-14.

20. Azevedo G, Mendonca S. Cancer in the female population in Brazil. Rev Saude Publica. 1993;27(1):68-75. [Portuguese].

21. Parkin DM, Almonte M, Bruni L, Clifford G, Curado MP, Pineros M. Burden and trends of type-specific human papillomavirus infections and related diseases in the Latin America and Caribbean region. Vaccine. 2008;26 (Suppl 11):L1-15.

22. Luciana S, Winkler J. Cervical cancer prevention in Peru: lessons learned from the Tati demonstration project. Washington, DC: Pan American Health Organization; 2006.

23. Paz Soldan VA, Lee FH, Carcamo C, Holmes KK, Garnett GP, Garcia P. Who is getting Pap smears in urban Peru? Int J Epidemiol. 2008;37(4):862-9.

24. Ministerio de Salud Argentina. Proyecto para el mejoramiento del Programa Nacional de Prevención de Cáncer Cérvico-Uterino en Argentina. Available from: http://www.msal. gov.ar/cancer-cervico-uterino/ Accessed 18 January 2011.

Manuscript received on 15 August 2011. Revised version accepted for publication on 17 January 2012.

RESUMEN Objetivo. Efectuar un análisis integral de las características epidemiológicas descriptivas del cáncer de cervicouterino invasor en América Latina y el Caribe mediante el análisis de datos de calidad de los registros de cáncer de la región, incluso datos que fueron excluidos de la publicación del Centro Internacional de Investigaciones sobre el Cáncer (CIIC), Incidencia del cáncer en cinco continentes, Vol. IX (CI5-IX).

Variación de la incidencia del cáncer cervicouterino en América Latina y el Caribe

Palabras clave
Métodos. En este estudio epidemiológico descriptivo se incluyeron 20 registros sobre el cáncer, de los cuales solo nueve fueron incluidos por el CIIC en el informe CI5-IX. Los datos sobre cáncer cervicouterino invasor diagnosticado entre 1998 y 2002 se obtuvieron a partir del CIIC. Se llevó a cabo una evaluación de la calidad de todos los registros específica para el cáncer cervicouterino, con independencia de que estuvieran incluidos en el informe CI5-IX o no. Los datos de 14 registros satisficieron los criterios de calidad y se analizaron. Se calcularon las tasas de incidencia y se compararon estas entre los registros.

Resultados. Entre los registros se comprobó una variación sustancial en las tasas de incidencia; las tasas normalizadas según la edad variaron entre 14,6 y 44,0 por 100000 mujeres por año. Las tasas de incidencia medias de cáncer cervicouterino fueron $10,4 \%$ mayores en los registros incluidos en el CI5-IX que en aquellos excluidos; sin embargo, esta diferencia no fue significativa $(P=0,541)$.

Conclusiones. En este estudio se compararon las tasas de cáncer cervicouterino de un grupo más diverso de países de América Latina y el Caribe que el comprendido en el informe CI5-IX. La heterogeneidad encontrada entre los registros destaca la importancia de examinar los datos de tantos registros como sea posible cuando se caracteriza el riesgo en una zona geográfica. Los datos de los países en desarrollo pueden usarse para conocer más a fondo la distribución del cáncer y permiten formular recomendaciones específicas para la región sobre el control y la prevención del cáncer, una vez que se ha comprobado la calidad de los datos. 